\title{
Atypical presentation and management of an epithelioid hemangioma: a case report and review of the literature
}

\author{
Claire J. Wiggins ${ }^{1,2}$, Rami P. Dibbs ${ }^{1,2}$, Erica L. Bartlett ${ }^{1}$, Daniel J. Ashton ${ }^{3}$ and Renata S. Maricevich ${ }^{1,2^{*}}$
}

\begin{abstract}
Background: Epithelioid hemangioma is a rare, benign vascular lesion classically presenting with painless nodules in the head and neck region. Hemangioma lesions are typically small, located within the dermis and subcutaneous tissue, and rarely exceed $10 \mathrm{~cm}$ in size. Complete surgical excision, with negative margins, is the recommended treatment as local recurrence is common. We describe an unusual presentation of epithelioid hemangioma that, to our knowledge, has not been previously described in the literature, epithelioid.
\end{abstract}

Case presentation: We report an atypical case of a large epithelioid hemangioma lesion with deep intramuscular involvement in a 16-year-old male. Ultrasound and MRI showed a hypervascular mass on the patient's left upper back, and biopsy confirmed the diagnosis. Treatment consisted of preoperative embolization followed by excision and local tissue rearrangement.

Conclusions: Epithelioid hemangiomas are considered uncommon in the pediatric population. Moreover, it is challenging to diagnose these lesions due to their similarities to other vascular anomalies. We aim to increase awareness of this condition and obtain more precision in diagnosis, thus standardizing the approach for those treating individuals with vascular anomalies.

Keywords: Epithelioid hemangioma, Vascular neoplasm, Intramuscular

\section{Background}

Epithelioid hemangioma (EH) was proposed as a distinct clinical finding in 1969, manifesting, clinically, as benign subcutaneous lesions [1]. These tumors are histologically defined by capillary vessel proliferation with eosinophilic infiltration and lymphoreticular hyperplasia, typically along a blood vessel. Classic presentation consists of "hobnail" or "tombstone" like endothelial cells [1, 2]. Although $\mathrm{EH}$ are considered uncommon, their prevalence is challenging to accurately measure due to the difficult

\footnotetext{
* Correspondence: renata.maricevich@bcm.edu

'Division of Plastic Surgery, Michael E. DeBakey Department of Surgery, Baylor College of Medicine, 6701 Fannin St. Suite 610.00, Houston, TX 77030, USA

2Division of Plastic Surgery, Department of Surgery, Texas Children's Hospital, Houston, TX, USA

Full list of author information is available at the end of the article
}

diagnosis of epithelioid vascular tumors and variability in the nomenclature [2,3].

EH commonly presents as red-to-purple painless nodules with a slight propensity for young to middle-aged females $[1,4,5]$. Cases have been reported globally, particularly among Asian and Caucasian populations. While the most prevalent site is the head and neck, EH has been identified in numerous anatomic locations, such as the lower back [2], penis [6], orbit [7], colon [8], oral cavity [9], thigh, and ankle [10]. Although typically a dermal or subcutaneous lesion, EH of larger vessels, heart, deep soft tissue, and bone have also been described [11-14].

There is no clear consensus on the pathogenesis of EH. Popular hypotheses include infectious and neoplastic causes, but the majority of studies support a reactive etiology $[4,5,15]$. Although debate over the cause of $\mathrm{EH}$

\section{Springer Open}

(๑) The Author(s). 2020 Open Access This article is licensed under a Creative Commons Attribution 4.0 International License, which permits use, sharing, adaptation, distribution and reproduction in any medium or format, as long as you give appropriate credit to the original author(s) and the source, provide a link to the Creative Commons licence, and indicate if changes were made. The images or other third party material in this article are included in the article's Creative Commons licence, unless indicated otherwise in a credit line to the material. If material is not included in the article's Creative Commons licence and your intended use is not permitted by statutory regulation or exceeds the permitted use, you will need to obtain permission directly from the copyright holder. To view a copy of this licence, visit http://creativecommons.org/licenses/by/4.0/. 
remains unresolved, surgical excision with negative margins has proven to be the treatment of choice. When completely removed, local recurrence is rare. However, with incomplete resection, 33\% of patients will recur either at the same site or a distant site along the same blood vessel $[4,5,15]$. Medical treatments have been used with mixed results; these include radiotherapy, chemotherapy, cryotherapy, steroid injections, and laser treatments [16-20].

Here, we report an unusual presentation of $\mathrm{EH}$ in a 16 -year-old male with the goal of clarifying the diagnosis and treatment strategies for this rare vascular anomaly by differentiating it from related conditions.

\section{Case presentation}

This patient is a 16-year-old male who presented with a painless, progressively enlarging mass over his left scapula. It was originally thought to represent a lipoma, and the patient underwent planned excision by an outside physician. However, during attempted excision, significant bleeding was encountered within the mass, and the procedure was aborted. A vascular lesion was suspected, and the patient was subsequently referred to the Vascular Anomalies Center in Houston, TX. His exam showed a $15 \times 15 \mathrm{~cm}$ well-circumscribed mass with firm attachment to the underlying soft tissue. There were no overlying skin changes other than a well-healed surgical scar. There had been significant growth since his attempted excision 7 months prior, which affected his ability to wear clothes and a backpack at school. Ultrasound showed a high-flow hypervascular, intramuscular mass. Magnetic resonance imaging (MRI) confirmed these findings in addition to multiple large feeding vessels (Fig. 1). He underwent core needle biopsy which showed rare spindle cells and plump endothelial cells, which was suggestive of $\mathrm{EH}$.

After multidisciplinary discussion, decision was made to proceed with excision. Preoperative embolization was
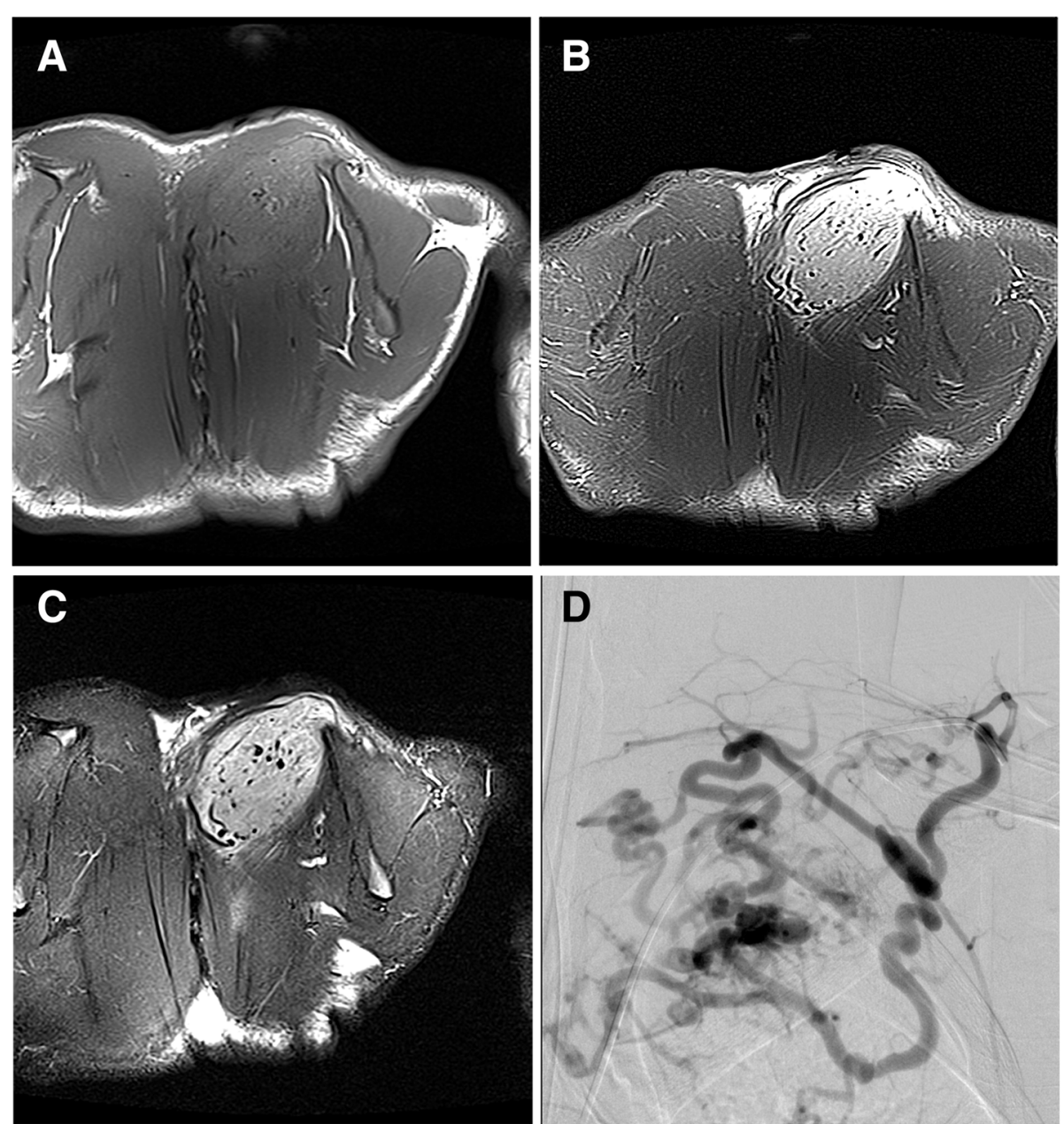

Fig. 1 a, b Pre- and post-contrast coronal T1-weighted images, respectively, demonstrate an avidly enhancing mass in the left upper back. c T2weighted coronal image with fat saturation demonstrates large flow voids consistent with abnormal arterial supply. $\mathbf{d}$ Frontal digital subtraction angiography demonstrates enlarged, abnormal feeding vessels arising from a branch of the subclavian artery 

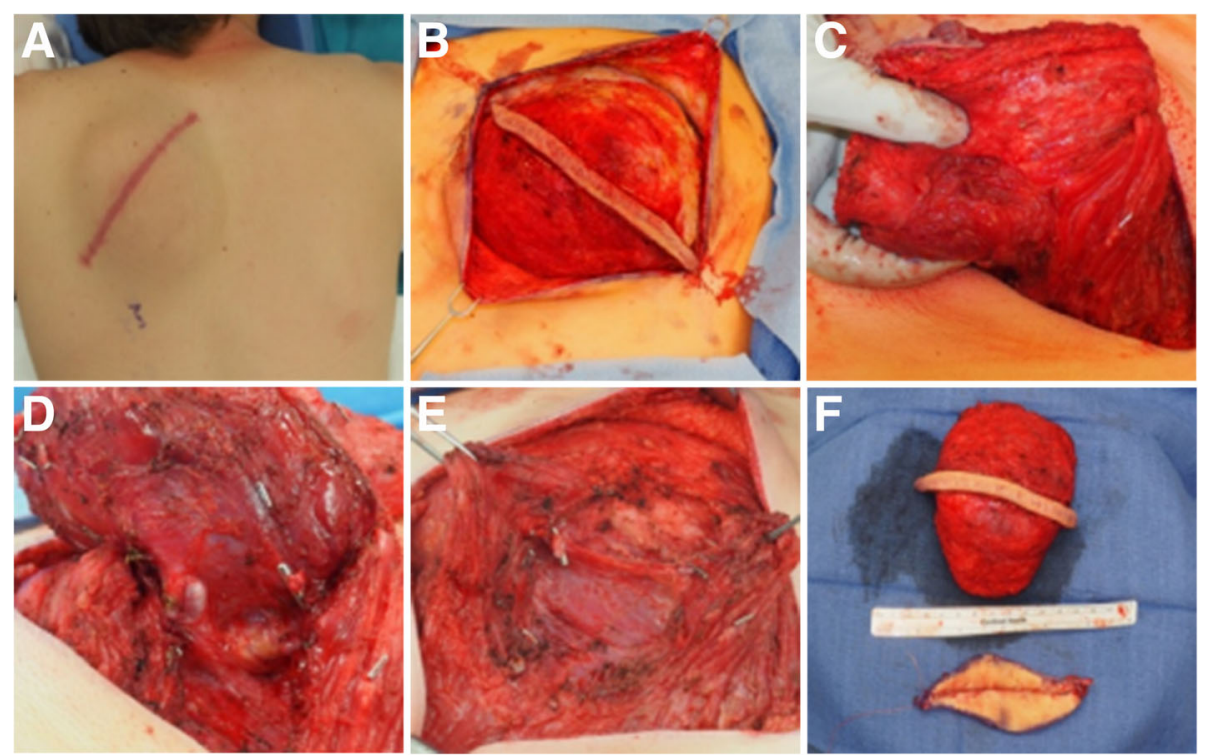

Fig. 2 Surgical removal of epithelioid hemangioma in a 16-year-old male. a Previous scar and deformity. b Lesion in situ. c Lesion deeply located, spreading muscle fibers. $\mathbf{d}$ Large vessels feeding and draining the lesion. e Split trapezius muscles after lesion excision. $\mathbf{f}$ Excised lesion with additional skin margin

performed the day prior to surgical excision to decrease inflow. Wide skin excision was performed together with portions of the trapezius and the rhomboid muscles to which the mass was deeply adherent. The mass was richly vascular with large arterial and venous branches appearing to originate deep to the trapezius muscle. However, the fascia did not look involved. The lesion was removed "en bloc" and sent for pathologic examination (Fig. 2). Reconstruction of the defect consisted of muscle re-approximation and local tissue rearrangement (Fig. 3). The patient was discharged the following day without postoperative complications.

Pathology showed a lobulated, richly vascular mass with prominent epithelioid cells and positive deep margins. Vascular channels were negative for Glut-1. Immunostain for D2-40 showed a minor lymphatic component. These findings were consistent and confirmed the diagnosis of EH. He recovered well and remained free from recurrence at his 6-month postoperative follow-up appointment (Fig. 4). While the patient initially voiced concern about attending school because of the size of the mass, he was pleased with the treatment plan and postoperative outcome.

\section{Discussion}

Although epithelioid hemangiomas were first described in the 1960s, inconsistencies still remain in diagnosis. $\mathrm{EH}$ lesions have been identified by many terms including

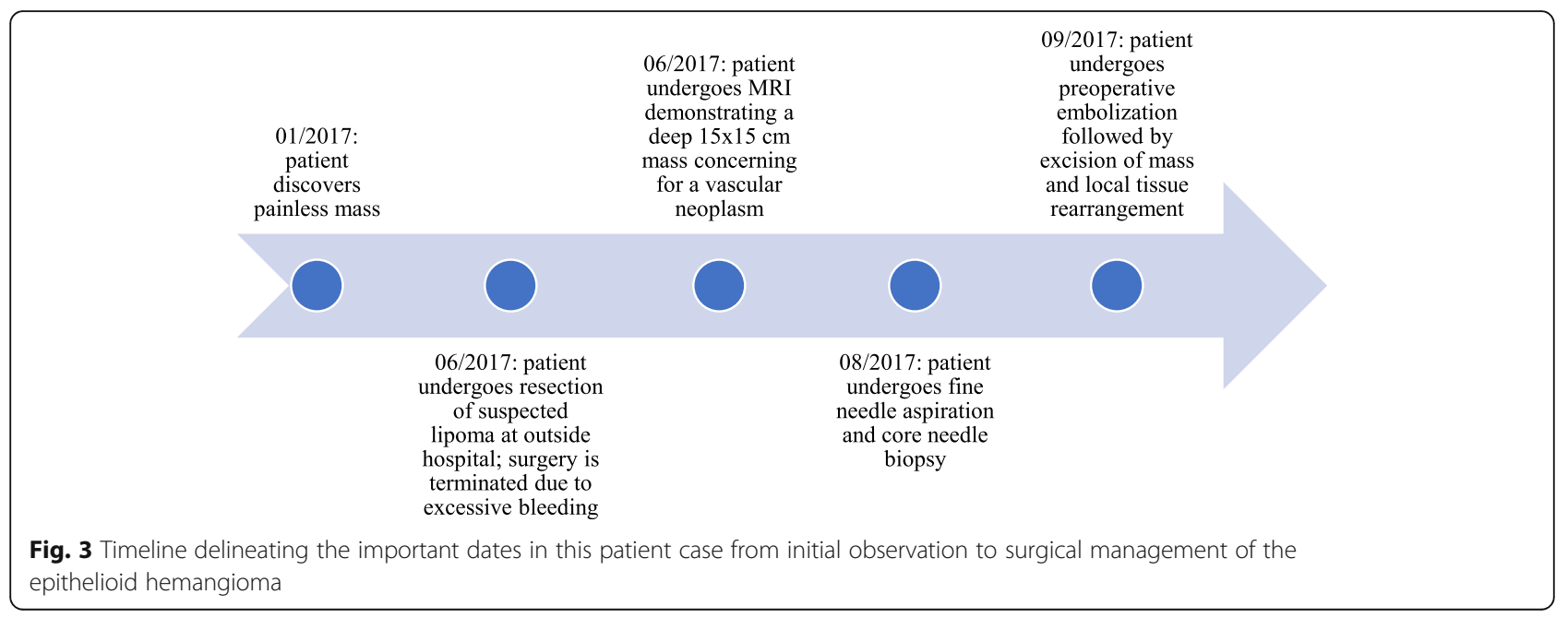




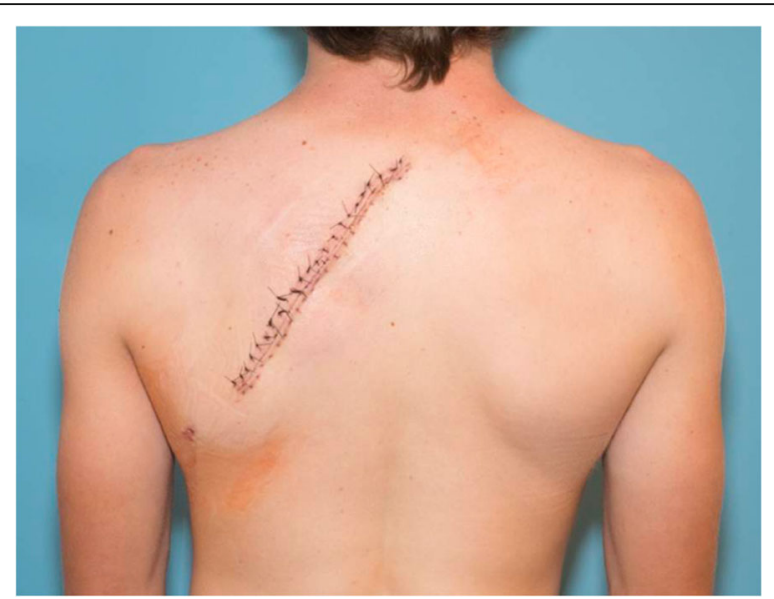

Fig. 4 Postoperative presentation of the patient demonstrating a healed scar without complications

angiolymphoid hyperplasia with eosinophilia $[5,21]$, intravenous atypical vascular proliferation [22], inflammatory angiomatous nodule [23], and histiocytoid hemangioma [24], which demonstrate the inconsistencies in nomenclature. The differential diagnosis includes benign, inflammatory conditions such as Kimura disease, IgG4-related skin disease, bacillary angiomatosis, cutaneous epithelioid angiomatous nodule, and malignant epithelial vascular tumors such as epithelioid sarcoma-like hemangioendothelioma, epithelioid hemangioendothelioma, and epithelioid angiosarcoma. Notably, Kimura disease is perhaps the most difficult to distinguish from $\mathrm{EH}$. In fact, they were originally considered to be different manifestations of the same disease [25]. Both Kimura's disease and EH may have some overlapping features, but Kimura's has been determined to be an allergic process, while $\mathrm{EH}$ lacks autoimmune features, making the unique histopathology of $\mathrm{EH}$ quite subtle [3, 26].

Our case represents an unusual example of $\mathrm{EH}$ in terms of size and degree of tissue involvement. The majority of documented $\mathrm{EH}$ lesions have diameters less than $3 \mathrm{~cm}$, with lesions larger than $10 \mathrm{~cm}$ rarely seen. The mass described in this case had grown to $15 \times 15$ $\mathrm{cm}$ by the time of excision, representing one of the largest $\mathrm{EH}$ lesions documented in the literature. $\mathrm{EH}$ lesions are typically present in dermal or subcutaneous tissue; however, in this case, the lesion originated deep to the underlying muscle. Although there has been a case reported of a cavernous hemangioma between the trapezius and splenius capitis muscles [27], a bone EH of the scapula reported [28], and an EH lesion $1.8 \times 1 \mathrm{~cm}$ presenting on the back [29], no such sizable EH lesions with intramuscular involvement has been reported.

Assessed by fine needle aspiration and frozen section, the tumor presented here was composed of predominantly lobulated arterial and venous channels with a minor lymphatic component. The lack of cytologic atypia, absence of necrosis, and presence of lobular architecture lessened the suspicion for a malignant mass, such as epithelioid hemangioendothelioma or epithelioid angiosarcoma. Testing for Glut-1 was negative, indicating that the lesion was unlikely an infantile hemangioma, and prominence of epithelioid endothelial cells in lobular channels helped to confirm the diagnosis of EH [30].

The tumor was surgically resected after confirming the final diagnosis. Pathological negative margins would have been ideal given the chance of local recurrence with incomplete excision. However, the defect would have been disfiguring and not justifiable for this benign disease process. Thus, the decision for active surveillance was elected after a long discussion with the patient and family.

The pathogenesis of EH still remains elusive, although the reactive theory has been supported in the literature. The lymphocytic infiltrate present in older $\mathrm{EH}$ lesions and a history of local trauma or damaged vessels lend support to this theory. One study examining 96 samples of $\mathrm{EH}$ lesions concluded that $\mathrm{EH}$ is likely reactive in nature due to a significant number of $\mathrm{EH}$ lesions presenting secondary to damage and repair of underlying vessels $[1,5]$. However, there is reason to consider other potential etiological factors as well. An EH case connected with human immunodeficiency virus suggests the potential for an infectious or immune-related etiology [31]. Cases have been described in which EH lesions have presented with either concurrent follicular mucinosis, peripheral $\mathrm{T}$ cell lymphoma, or detected $\mathrm{T}$ cell receptor gene mutation, suggesting a potential underlying neoplastic cause of EH [32-35]. The abnormal vessel proliferation of EH may also be derived from FOS oncogenic activation, which supports a neoplastic etiology [36].

Further investigation is warranted to determine the true incidence of $\mathrm{EH}$ worldwide. Additionally, higher quality education is necessary to differentiate between similar vascular anomalies. New tools, such as nextgeneration sequencing, can help remedy this diagnostic challenge by differentiating tumors based on their own specific deleterious variants. This has already shown promise in differentiating epithelioid angiosarcoma and $\mathrm{EH}$ [37]. Further investigation into the potential etiologies, such as the recent connection found between $\mathrm{EH}$ and the FOS gene mutation, could reveal more information on the causes and risk factors associated with these lesions [36, 38].

Both across specialties and within associated disciplines, it has been shown that there is inconsistency in the terminology used to describe vascular anomalies [39]. Obtaining an accurate diagnosis with appropriate terminology is important for properly managing patients. Heightened awareness of the variety of clinical presentations, 
different terminologies, and diagnostic tools is essential to improving patients' prognoses for all vascular anomalies.

\section{Conclusion}

Epithelioid hemangiomas are benign vascular tumors that are rarely observed within the pediatric population. Furthermore, discerning its prevalence is difficult due to the challenging nature of diagnosing vascular tumors and the similarities between these vascular anomalies. Diagnosis is generally suspected via ultrasound and MRI and confirmed by biopsy. For large EH that are deeply adherent to muscle, we found that treatment with preoperative embolization followed by excision provided excellent postoperative results with minimal morbidity.

\section{Abbreviations}

EH: Epithelioid hemangioma; MRI: Magnetic resonance imaging

\section{Acknowledgements}

Not applicable

\section{Authors' contributions}

$\mathrm{CW}$ and $\mathrm{EB}$ analyzed and interpreted the patient data regarding the epithelioid hemangioma. DA provided radiology image to the manuscript. All authors were major contributors to writing the manuscript. All authors read and approved the final manuscript.

\section{Funding}

Not applicable

\section{Availability of data and materials}

Available upon request

Ethics approval and consent to participate

Not applicable

\section{Consent for publication}

Formal written consent was obtained from the patient's parent

\section{Competing interests}

The authors declare that they have no competing interests.

\section{Author details}

${ }^{1}$ Division of Plastic Surgery, Michael E. DeBakey Department of Surgery, Baylor College of Medicine, 6701 Fannin St. Suite 610.00, Houston, TX 77030, USA. ${ }^{2}$ Division of Plastic Surgery, Department of Surgery, Texas Children's Hospital, Houston, TX, USA. ${ }^{3}$ Division of Pediatric Radiology, Department of Radiology, Arkansas Children's Hospital, Little Rock, AR, USA

Received: 24 September 2020 Accepted: 24 November 2020 Published online: 21 December 2020

\section{References}

1. Wells GC, Whimster IW. Subcutaneous angiolymphoid hyperplasia with eosinophilia. Br J Dermatol. 1969;81(1):1-14.

2. Kurihara $Y$, Inoue $H$, Kiryu $H$, Furue M. Epithelioid hemangioma (angiolymphoid hyperplasia with eosinophilia) in zosteriform distribution. Indian J Dermatol. 2012;57(5):401-3.

3. Ko JS, Billings SD. Diagnostically challenging epithelioid vascular tumors. Surg Pathol Clin. 2015;8(3):331-51.

4. Olsen TG, Helwig EB. Angiolymphoid hyperplasia with eosinophilia. A clinicopathologic study of 116 patients. J Am Acad Dermatol. 1985;12(5 Pt 1):781-96

5. Fetsch JF, Weiss SW. Observations concerning the pathogenesis of epithelioid hemangioma (angiolymphoid hyperplasia). Modern Pathol. 1991; 4(4):449-55
6. Fetsch JF, Sesterhenn IA, Miettinen M, Davis CJ. Epithelioid hemangioma of the penis: a clinicopathologic and immunohistochemical analysis of 19 cases, with special reference to exuberant examples often confused with epithelioid hemangioendothelioma and epithelioid angiosarcoma. Am J Surg Pathol. 2004;28(4):523-33.

7. Fernandes BF, Al-Mujaini A, Petrogiannis-Haliotis T, Al-Kandari A, Arthurs B, Burnier MN Jr. Epithelioid hemangioma (angiolymphoid hyperplasia with eosinophilia) of the orbit: a case report. J Med Case Rep. 2007;1:30.

8. Berney DM, Griffiths MP, Brown CL. Angiolymphoid hyperplasia with eosinophilia in the colon: a novel cause of rectal bleeding. J Clin Pathol. 1997;50(7):611-3.

9. Park Y, Chung J, Cho C-G. Angiolymphoid hyperplasia with eosinophilia of the tongue: report of a case and review of the literature. Oral Oncol. 2002 38(1):103-6.

10. Fernandez-Flores A, Cassarino DS. Three unusual histopathological presentations of angiolymphoid hyperplasia with eosinophilia. J Cutaneous Pathol. 2017:44(3):300-6.

11. Evans HL, Raymond AK, Ayala AG. Vascular tumors of bone: a study of 17 cases other than ordinary hemangioma, with an evaluation of the relationship of hemangioendothelioma of bone to epithelioid hemangioma epithelioid hemangioendothelioma, and high-grade angiosarcoma. Hum Pathol. 2003;34(7):680-9.

12. Ragazzi M, Falco G, Valli R, Rocco N, Bordoni D, Cadenelli P, et al. Epithelioid hemangioma of brachial artery: report of a case and review of the literature. Open Med. 2015;10(1):502-7.

13. Zhou Q, Lu L, Fu Y, Xiang K, Xu L. Epithelioid hemangioma of bone: a report of two special cases and a literature review. Skeletal Radiol. 2016; 45(12):1723-7.

14. Machado I, Chong A, Serrano A, Naranjo Ugalde AM, Pineda D, Savón L, et al. Epithelioid hemangioma (angiolymphoid hyperplasia with eosinophilia) of the heart with peripheral eosinophilia and nephrotic syndrome. Int J Surg Pathol. 2016;24(1):59-65.

15. Baghestani S, Firooz A, Ghazisaidi MR. A refractory case of angiolymphoid hyperplasia with eosinophilia successfully treated by surgery. J Dermatol Treatment. 2011;22(1):49-51.

16. Abrahamson TG, Davis DA. Angiolymphoid hyperplasia with eosinophilia responsive to pulsed dye laser. J Am Acad Dermatol. 2003;49(2):195-6.

17. Kaur T, Sandhu K, Gupta S, Kanwar A, Kumar B. Treatment of angiolymphoid hyperplasia with eosinophilia with the carbon dioxide laser. J Dermatol Treatment. 2004;15(5):328-30.

18. Woźniacka A, Omulecki A, Torzecka JD. Cryotherapy in the treatment of angiolymphoid hyperplasia with eosinophilia. Med Sci Monitor. 2003;9(1): CS1-4.

19. Lembo S, Balato A, Cirillo T, Balato N. A long-term follow-up of angiolymphoid hyperplasia with eosinophilia treated by corticosteroids: when a traditional therapy is still up-to-date. Case Rep Dermatol. 2011;3(1):64-7.

20. Conill C, Toscas I, Mascaro J, Vilalta A, Mascaro J. Angiolymphoid hyperplasia with eosinophilia of the nail bed and bone: successful treatment with radiation therapy. J Eur Acad Dermatol Venereol. 2004;18(5):584-5.

21. Castro C, Winkelmann RK. Angiolymphoid hyperplasia with eosinophilia in the skin. Cancer. 1974:34(5):1696-705.

22. Rosai J, Akerman LR. Intravenous atypical vascular proliferation. Arch Dermatol. 1974:109(5):714

23. Jones EW, Bleehen SS. Inflammatory angiomatous nodules with abnormal blood vessels occurring about the ears and scalp (pseudo or atypical pyogenic granuloma). Br J Dermatol. 1969;81(11):804-16.

24. Rosai J, Gold J, Landy R. The histiocytoid hemangiomas. A unifying concept embracing several previously described entities of skin, soft tissue, large vessels, bone, and heart. Hum Pathol. 1979;10(6):707-30.

25. Guo R, Gavino ACP. Angiolymphoid hyperplasia with eosinophilia. Arch Pathol Lab Med. 2015;139(5):683-6.

26. Googe PB, Harris NL, Mihm MC. Kimura's disease and angiolymphoid hyperplasia with eosinophilia: two distinct histopathological entities. J Cutan Pathol. 1987:14(5):263-71.

27. Choi WH, Lee CJ, Oh SH, Chung BS, Rhim JK, Kwon KW. Cavernous hemangioma occurred between the trapezius and splenius capitis muscle. Korean J Spine. 2012;9(2):118

28. Tsikopoulos K, Perdikakis E, Georgiannos D, Bisbinas I. Epithelioid hemangioma of the scapula treated with chemoembolization and microwave ablation: a case report. Acta Orthop Traumatol Turc. 2018:52(2): 157-16. 
29. Li S-L, Han J-D. Solitary nodule of angiolymphoid hyperplasia with eosinophilia of the back masquerading as pyogenic granuloma. Mol Clin Oncol. 2017;7(5):874-6.

30. Leon-Villapalos J, Wolfe K, Kangesu L. GLUT-1: an extra diagnostic tool to differentiate between haemangiomas and vascular malformations. $\mathrm{Br} J$ Plastic Surg. 2005;58(3):348-52.

31. D'Offizi G, Ferrara R, Donati P, Bellomo P, Paganelli R. Angiolymphoid hyperplasia with eosinophils in HIV infection. AIDS (London, England). 1995; 9(7):813-4.

32. Joshi R. Angiolymphoid hyperplasia with follicular mucinosis. Indian J Dermatol Venereol Leprol. n.d.;73(5):346-7.

33. Andreae J, Galle C, Magdorf K, Staab D, Meyer L, Goldman M, Querfeld U. Severe atherosclerosis of the aorta and development of peripheral T-cell lymphoma in an adolescent with angiolymphoid hyperplasia with eosinophilia. Br J Dermatol. 2005;152(5):1033-8.

34. Kempf W, Haeffner AC, Zepter K, Sander CA, Flaig MJ, Mueller B, et al. Angiolymphoid hyperplasia with eosinophilia: evidence for a T-cell lymphoproliferative origin. Hum Pathol. 2002;33(10):1023-9.

35. Gonzalez-Cuyar LF, Tavora F, Zhao XF, Wang G, Auerbach A, Aguilera N, Burke AP. Angiolymphoid hyperplasia with eosinophilia developing in a patient with history of peripheral T-cell lymphoma: evidence for multicentric T-cell lymphoproliferative process. Diagn Pathol. 2008;3:22.

36. van IJzendoorn, D. G. P., Forghany, Z., Liebelt, F., Vertegaal, A. C., Jochemsen, A. G., Bovée, J. V. M. G., ... Baker, D. A. (2017). Functional analyses of a human vascular tumor FOS variant identify a novel degradation mechanism and a link to tumorigenesis. J Biol Chem, 292(52), 21282-21290.

37. Subramaniam MM, Salleh NL, Wu B, Rozario MA, Lim H, Puhaindran ME, et al. Primary epithelioid angiosarcoma of finger masquerading as epithelioid hemangioma. Appl Immunohistochem Mol Morphol. 2018;26(1): e7-e13.

38. Llamas-Velasco M, Kempf W, Cota C et al. Multiple eruptive epithelioid hemangiomas: A subset of cutaneous cellular epithelioid hemangioma with expression of FOS-B. Am J Surg Pathol. 2019:43(1):26-34.

39. Pahl KS, Kim K, Sams C, Alvarez H, Smith SV, Blatt J. Inconsistency in classifying vascular anomalies: what's in a name? Pediatr Blood Cancer. 2018;65(3):e26836

\section{Publisher's Note}

Springer Nature remains neutral with regard to jurisdictional claims in published maps and institutional affiliations.

\section{Submit your manuscript to a SpringerOpen ${ }^{\circ}$ journal and benefit from:}

- Convenient online submission

- Rigorous peer review

- Open access: articles freely available online

- High visibility within the field

- Retaining the copyright to your article

Submit your next manuscript at $\boldsymbol{\nabla}$ springeropen.com 